Case Report

\title{
Dendritic Fibromyxolipoma of the Pyriform Sinus: A Case Report and Review of the Literature
}

\author{
Abdulrahim AlAbdulsalam ${ }^{1}$ and Maha Arafah ${ }^{2}$ \\ ${ }^{1}$ Section of Pathology, Department of Biomedical Sciences, College of Medicine, King Faisal University, Al-Ahsa, Saudi Arabia \\ ${ }^{2}$ Section of Anatomic Pathology, Department of Pathology and Laboratory Medicine, College of Medicine, \\ King Saud University, Riyadh, Saudi Arabia \\ Correspondence should be addressed to Abdulrahim AlAbdulsalam; dr.abdulrahim2@gmail.com
}

Received 7 October 2016; Accepted 28 November 2016

Academic Editor: Yoh Dobashi

Copyright (C) 2016 A. AlAbdulsalam and M. Arafah. This is an open access article distributed under the Creative Commons Attribution License, which permits unrestricted use, distribution, and reproduction in any medium, provided the original work is properly cited.

\begin{abstract}
Dendritic fibromyxolipoma is a rare and distinctive soft tissue neoplasm that is considered by many authors as a variant of spindle cell lipoma and characterized by the presence of dendritic cytoplasmic processes, plexiform vascular pattern, and keloidal collagen. It has never been reported in the larynx and hypopharynx. Its rarity and the potential to mistake it as a more clinically aggressive myxoid soft tissue neoplasm highlight the importance of its recognition. Here, a case of a dendritic fibromyxolipoma of the pyriform sinus in a 38-year-old male who presented with dysphagia, change of voice, and stridor is reported. A review of the literature, including histopathologic features and differential diagnosis, is also included.
\end{abstract}

\section{Introduction}

Lipomas are the most common soft tissue tumors in adults. Spindle cell lipoma (SCL) is an uncommon variant that has a characteristic clinical setting. It usually presents as a mass in the posterior neck and shoulder region of men between the ages of 40 and 50. It has also been described in many other locations. About 7 cases have been reported in the larynx and hypopharynx. Dendritic fibromyxolipoma (DFML) is a rare and distinctive tumor that is considered by many as a variant of spindle cell lipoma characterized by extensive myxoid change and the presence of stellate cells with dendritic processes. A total of 21 cases have been reported, none of which are in the larynx and hypopharynx. Here, we describe a case of dendritic fibromyxolipoma of the pyriform sinus, with review of the literature.

\section{Case Presentation}

A 38-year-old male who is known to be a heavy smoker for 10 years presented with progressive dysphagia for one year, associated with change of voice, stridor, and sleep disturbance in the last three months. He has no past history of trauma or surgery in the head and neck and no family history of cancer. Laryngoscopic examination showed a large oval mass originating from the left pyriform sinus and causing narrowing of both the hypopharynx and larynx. The clinical impression was that of a retention cyst.

Contrast-enhanced CT scan of the head and neck was performed. It confirmed the presence of the mass in the hypopharynx, measuring $3.4 \times 3.4 \times 2.8 \mathrm{~cm}$. It was welldefined, hypodense, mostly homogenous, and nonenhancing, with a very focal area of contrast enhancement (Figure 1).

A microlaryngoscopy with debulking of the mass by $\mathrm{CO}_{2}$ laser was performed. Gross examination revealed multiple pieces of soft yellow-tan and glistening tissue measuring 7.5 $\times 6.5 \times 0.5 \mathrm{~cm}$ in aggregate (Figure 2).

On microscopic examination, the pieces are composed of a hypocellular spindle cell neoplasm with abundant myxoid background and plexiform blood vessels (Figure 3(A)). Few mature adipocytes are present as single cells or as small clusters scattered throughout the lesion (Figure 3(B)). The spindle cells have a stellate shape with small oval nuclei, inconspicuous nucleoli, and multiple dendritic cytoplasmic processes (Figure $4(\mathrm{~A})$ ). Some areas have a more fibrotic background with thick (ropy) collagen bundles. Numerous 
TABLE 1: Clinical findings of all reported cases of DFML.

\begin{tabular}{|c|c|c|c|c|c|c|c|}
\hline Number & Author & $\begin{array}{c}\text { Year } \\
\text { reported }\end{array}$ & Age & Sex & Location & Size $(\mathrm{cm})$ & Follow-up \\
\hline 1 & Suster $[1]$ & 1998 & 33 & M & Left posterior shoulder, acromion region & 11 & NA \\
\hline 2 & & & 54 & M & Right posterior neck & 5 & NA \\
\hline 3 & & & 58 & M & Right shoulder & 7.5 & 7 years, NRM \\
\hline 4 & & & 63 & M & Upper back & 6 & NA \\
\hline 5 & & & 66 & M & Back of neck & 8 & NA \\
\hline 6 & & & 66 & M & Posterior axillary fold & 9 & NA \\
\hline 7 & & & 70 & M & Right nasal area & 2 & 11 years, NRM \\
\hline 8 & & & 73 & M & Right posterior neck & 7 & 13 years, NRM \\
\hline 9 & & & 77 & M & Back of neck & 3 & 5 years, NRM \\
\hline 10 & & & 79 & M & Right chest wall & 3.5 & $\begin{array}{l}\text { Died of metastatic } \\
\text { lung cancer }\end{array}$ \\
\hline 11 & & & 81 & M & Left chest wall & 3.5 & 5 years, NRM \\
\hline 12 & & & 50 & $\mathrm{~F}$ & Right upper back & 6 & NA \\
\hline 13 & Karim [2] & 2003 & 73 & M & $\begin{array}{l}\text { Right shoulder, between infraspinatus and deltoid } \\
\text { muscles }\end{array}$ & 13 & 8 months, NRM \\
\hline 14 & Maskery [3] & 2011 & 36 & $\mathrm{~F}$ & Lower lip & 2 & 2 years, NRM \\
\hline 15 & Dahlin [4] & 2012 & 65 & $\mathrm{~F}$ & Left forearm, adherent to median nerve & 3.2 & NA \\
\hline 16 & Zhang [5] & 2013 & 32 & $\mathrm{~F}$ & Right inguinal and perineum region & 24 & 9 months, NRM \\
\hline 17 & Wong [6] & 2014 & 67 & M & Left shoulder & 7 & 4 months, NRM \\
\hline 18 & Han [7] & 2014 & 69 & M & Nasal tip & 1 & NA \\
\hline 19 & $\mathrm{Xu}[8]$ & 2015 & 24 & M & Left shoulder, triceps brachii (intramuscular) & 14 & 4 years, NRM \\
\hline 20 & Liu [9] & 2015 & 53 & M & Right back, latissimus dorsi (intramuscular) & 2 & 1 year, NRM \\
\hline 21 & Cilogu [10] & 2016 & 59 & $\mathrm{~F}$ & Left inguinal region & 17 & 3 years, NRM \\
\hline
\end{tabular}

$\mathrm{M}$, male; F, female; NA, information not available; NRM, no recurrence or metastasis.

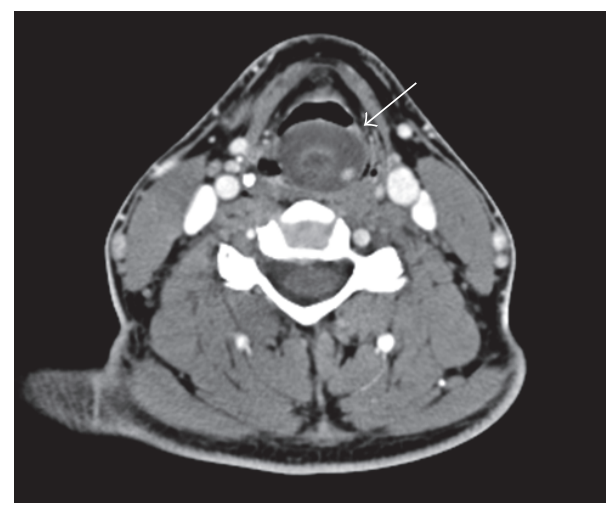

FIgURE 1: Contrast-enhanced CT scan of the neck. A well circumscribed, focally enhancing mass is noted in the left pyriform sinus (arrow).

mast cells were also present. There were no lipoblasts and no appreciable mitotic activity in the lesion. Immunohistochemistry showed that the spindle cells were strongly positive for vimentin, $\mathrm{CD} 34$, and $\mathrm{Bcl}-2$ and negative for desmin, alpha smooth-muscle actin, and S-100 protein. The dendritic cytoplasmic processes were highlighted by CD34

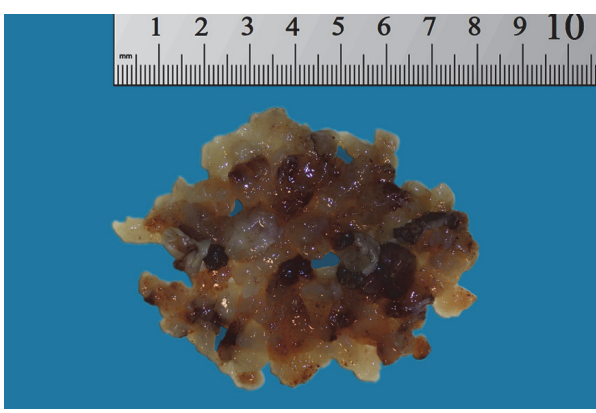

Figure 2: Gross appearance of the specimen.

(Figure 4(B)) and vimentin. Ki-67 labeling index was very low. The adipocytes were positive for S-100 protein.

\section{Discussion}

DFML has been initially described by Suster et al. in 1998 in a 12-case series report [1]. Since then, about 9 additional cases have been reported in the English literature and cited in PUBMED (Table 1) [2-10]. The age ranges from 24 to 81 years, with a median age of 65 years. Male to female ratio is $4: 1$. The most common locations are the subcutaneous 

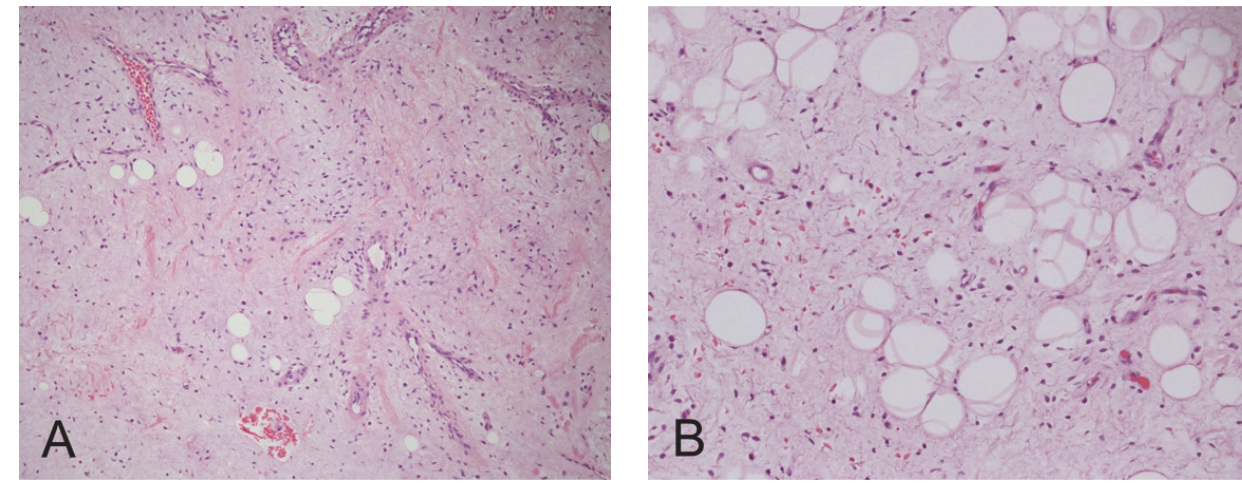

Figure 3: (A) Hematoxylin and eosin- (H\&E-) stained sections showed a hypocellular neoplasm with myxoid background, ropy collagen bundles, and plexiform blood vessels (100x). (B) Mature adipocytes with scattered bland spindle cells (400x).
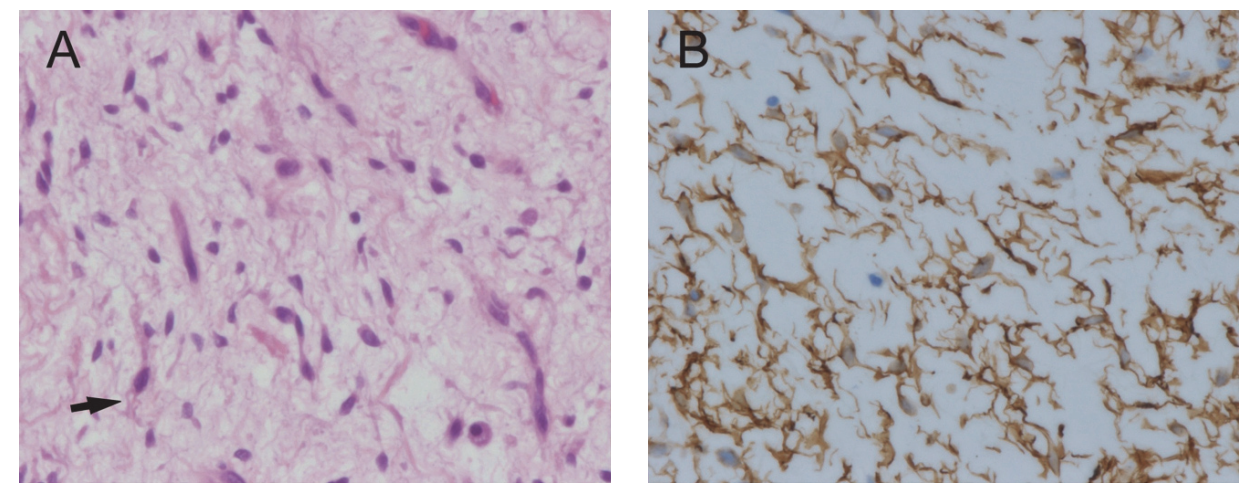

FIGURE 4: (A) H\&E-stained section showed the dendritic cytoplasmic processes of the spindle cells (arrow) (600x). (B) Immunohistochemistry for CD34 also highlights the dendritic cytoplasmic processes.

tissue and muscular fascia of the shoulder, neck, and back. Other reported locations include the nasal tip, lip, forearm, and intramuscular location. The lesion is usually wellcircumscribed and slow growing, with a gelatinous gray to yellow cut surface.

Microscopically, it is composed of bland-appearing spindle cells with abundant myxoid background, prominent anastomosing blood vessels, areas of ropy collagen deposition, and prominent mast cells. The cells have oval nuclei and contain multiple dendritic cytoplasmic processes that are best highlighted by immunohistochemistry for CD34 and vimentin. CD99 positivity has been reported in a case [3]. S100 is negative.

There are two opinions regarding the nature of this lesion. The first is that it represents a peculiar variant of spindle cell lipoma with extensive myxoid change. Evidence supporting this claim includes the similarity of clinical characteristics including age, gender, and location, similar morphologic features, and immunophenotype with identical clinical outcome. Wong et al. [6] demonstrated the presence of 13q14.3 deletion in one case of DFML, a recurrent finding in SCL. We speculate that many cases previously diagnosed as myxoid lipoma or myxolipoma belong to the category of DFML. DFML is morphologically distinguished from spindle cell lipoma by the presence of dendritic cytoplasmic processes, plexiform vascular pattern, and abundant keloidal collagen.
The other view is that it represents a tumor with combined features of SCL and solitary fibrous tumor (SFT) or an intermediate form between these two entities [3, 9]. Evidence supporting this view includes the similar immunohistochemical profile (positivity for CD34, Bcl-2, and CD99 in some cases). In addition, myxoid change has been reported in SFT [11]. However, SFT lacks the adipose tissue component of DFML and has prominent hemangiopericytoma-like vessels.

DFML can be confused with other more clinically aggressive neoplasms, including myxoid liposarcoma (MLS), lowgrade fibromyxoid sarcoma (LFMS), and myxofibrosarcoma, especially the low-grade type, highlighting the importance of its recognition. MLS typically develops in the deep soft tissues of lower extremities. It shares many features with DFML including plexiform vascular pattern and abundant myxoid matrix. However, the lack of lipoblasts and atypical cells, negativity for S-100 and positivity for CD34, differentiates it from DFML. In addition, about $95 \%$ of cases of MLS harbor a recurrent translocation involving DDIT3 gene at chromosome 12 [12]. LFMS is composed of alternating fibrous and myxoid areas with low to moderate cellularity, bland spindle cells, and a characteristic swirling, whorled growth pattern [13]. It shows positivity for MUC-4 by immunohistochemistry in virtually all cases [14]. Myxofibrosarcoma is characterized by presentation in elderly patients and consists of a hypocellular neoplasm with myxoid background. It is 
distinguished by the presence of atypical and hyperchromatic cells and curvilinear blood vessels [15].

Follow-up data on all available reported cases showed no recurrence or metastases, with periods ranging from 4 months to 13 years.

In conclusion, DFML is a rare tumor that shares many similarities with spindle cell lipoma. This study presents the first case reported in the hypopharynx. It is important to be aware of this lesion in order to not misdiagnose it as other clinically more aggressive neoplasms such as myxoid liposarcoma and low-grade fibromyxoid sarcoma. More studies including molecular testing for $13 \mathrm{q}$ deletion and NAB2STAT6 fusion [11] in cases of DFML would help to accurately identify the nature of this neoplasm.

\section{Competing Interests}

The authors declare that there is no conflict of interests regarding the publication of this paper.

\section{References}

[1] S. Suster, C. Fisher, and C. A. Moran, "Dendritic fibromyxolipoma: clinicopathologic study of a distinctive benign soft tissue lesion that may be mistaken for a sarcoma," Annals of Diagnostic Pathology, vol. 2, no. 2, pp. 111-120, 1998.

[2] R. Z. Karim, S. W. McCarthy, A. A. Palmer, S. F. Bonar, and R. A. Scolyer, "Intramuscular dendritic fibromyxolipoma: myxoid variant of spindle cell lipoma?” Pathology International, vol. 53, no. 4, pp. 252-258, 2003.

[3] A. Al-Maskery, S. M. Al-Sidairy, and A. S. Al-Hamadani, "Dendritic myxofibrolipoma: often misdiagnosed as sarcoma," Craniomaxillofacial Trauma and Reconstruction, vol. 4, no. 3, pp. 171-174, 2011.

[4] L. B. Dahlin and O. Ljungberg, "Dendritic fibromyxolipoma adherent to the median nerve in the forearm," Journal of Plastic Surgery and Hand Surgery, vol. 46, no. 2, pp. 120-123, 2012.

[5] X. J. Zhang, S. Zhou, K. Nie, D. F. Chen, G. J. Kui, and X. H. Zhang, "Dendritic fibromyxolipoma in the right inguinal and perineum regions: a case report and review of the literature," Diagnostic Pathology, vol. 8, no. 1, article 157, 2013.

[6] Y.-P. Wong, W. K. Chia, S. F. Low, N. H. Mohamed-Haflah, and N. A. Sharifah, "Dendritic fibromyxolipoma: a variant of spindle cell lipoma with extensive myxoid change, with cytogenetic evidence," Pathology International, vol. 64, no. 7, pp. 346-351, 2014.

[7] X.-C. Han, L.-Q. Zheng, and X.-L. Shang, "Dendritic fibromyxolipoma on the nasal tip in an old patient," International Journal of Clinical and Experimental Pathology, vol. 7, no. 10, pp. 70647067, 2014.

[8] X. Xu, W. Xiong, L. Zheng, and J. Yu, "Intramuscular dendritic fibromyxolipoma in a 24 -year-old male: a case report and review of the literature," Oncology Letters, vol. 9, no. 2, pp. 583586, 2015.

[9] S. Liu, X. Wang, B. Lei et al., "Dendritic fibromyxolipoma in the latissimus dorsi: a case report and review of the literature," International Journal of Clinical and Experimental Pathology, vol. 8, no. 7, pp. 8650-8654, 2015.

[10] S. Ciloglu, A. Duran, E. Keskin, and A. Yigit, "Dendritic fibromyxolipoma of left inguinal region," Indian Journal of Pathology and Microbiology, vol. 59, no. 2, pp. 250-251, 2016.
[11] R. J. Vogels, M. Vlenterie, Y. M. Versleijen-Jonkers et al., "Solitary fibrous tumor-clinicopathologic, immunohistochemical and molecular analysis of 28 cases," Diagnostic Pathology, vol. 9, article 224, 2014.

[12] S. Narendra, A. Valente, J. Tull, and S. Zhang, "DDIT3 gene break-apart as a molecular marker for diagnosis of myxoid liposarcoma-assay validation and clinical experience," Diagnostic Molecular Pathology, vol. 20, no. 4, pp. 218-224, 2011.

[13] H. L. Evans, "Low-grade fibromyxoid sarcoma: a clinicopathologic study of 33 cases with long-term follow-up," The American Journal of Surgical Pathology, vol. 35, no. 10, pp. 1450-1462, 2011.

[14] L. A. Doyle, E. Möller, P. D. Cin, C. D. M. Fletcher, F. Mertens, and J. L. Hornick, "MUC4 is a highly sensitive and specific marker for low-grade fibromyxoid sarcoma," The American Journal of Surgical Pathology, vol. 35, no. 5, pp. 733-741, 2011.

[15] T. Mentzel, P. C. W. Hogendoorn, and H. Y. Huang, "Myxofibrosarcoma," in WHO Classification of Tumours of Soft Tissue and Bone, C. D. M. Fletcher, J. A. Bridge, P. C. W. Hogendoorn, and F. Mertens, Eds., pp. 93-94, IARC, Lyon, France, 2013. 


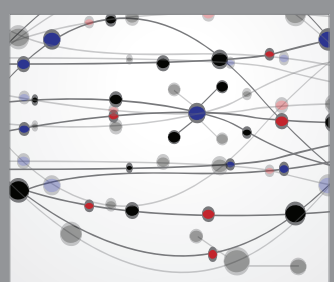

The Scientific World Journal
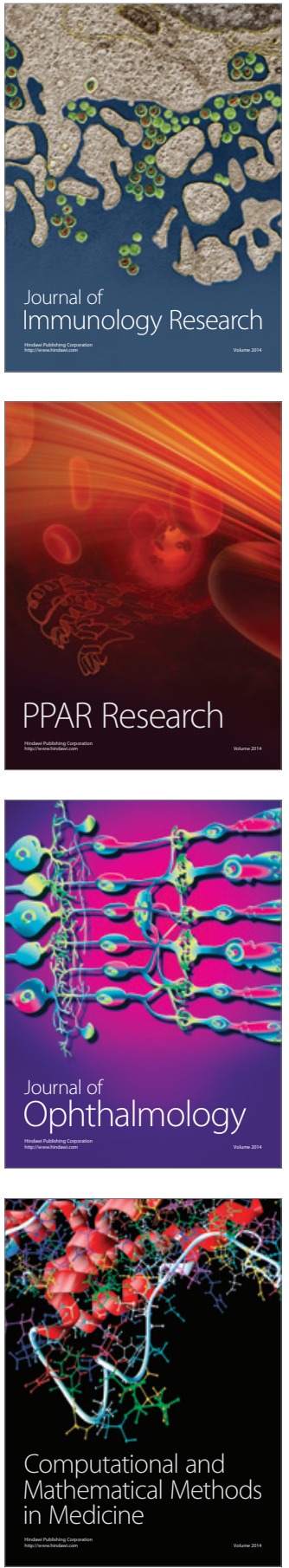

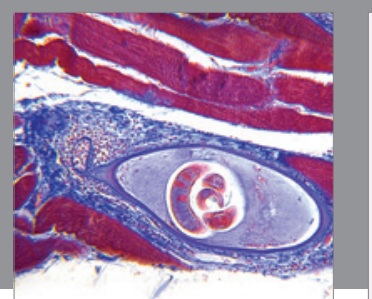

Gastroenterology Research and Practice

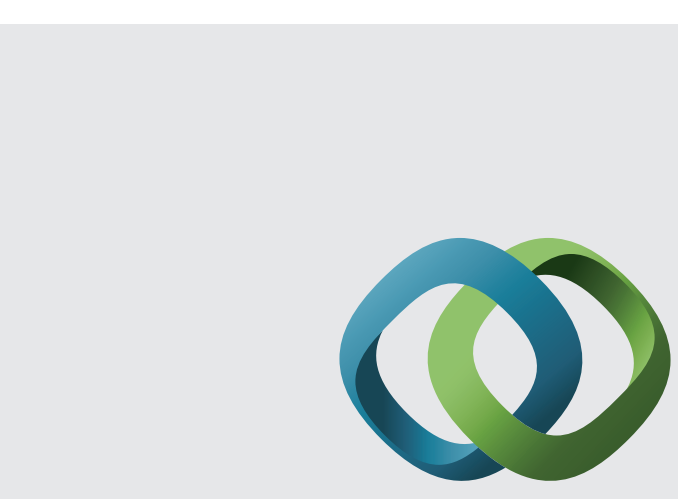

\section{Hindawi}

Submit your manuscripts at

http://www.hindawi.com
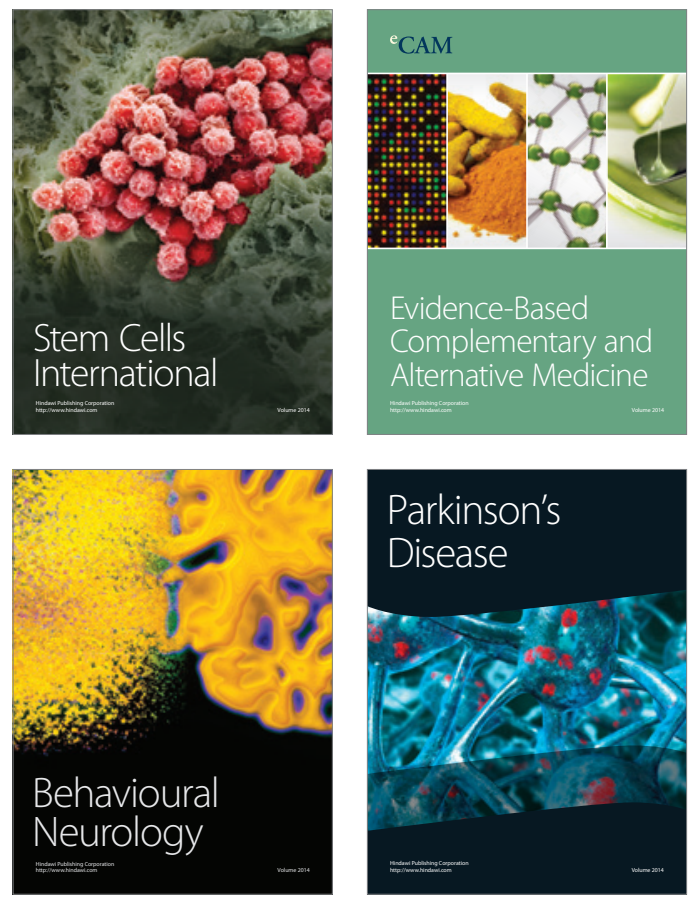
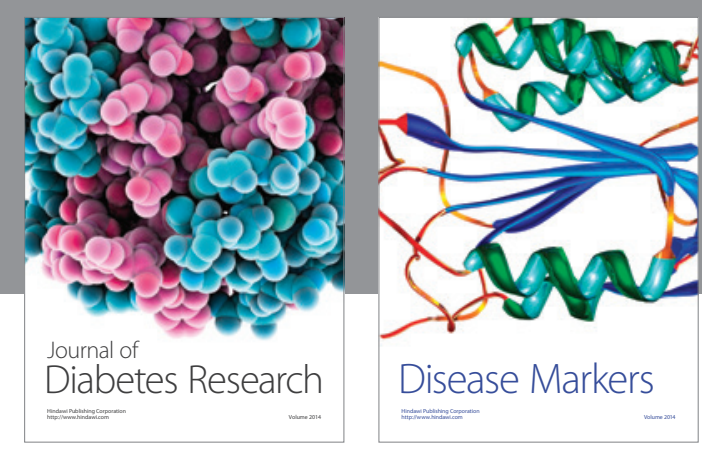

Disease Markers
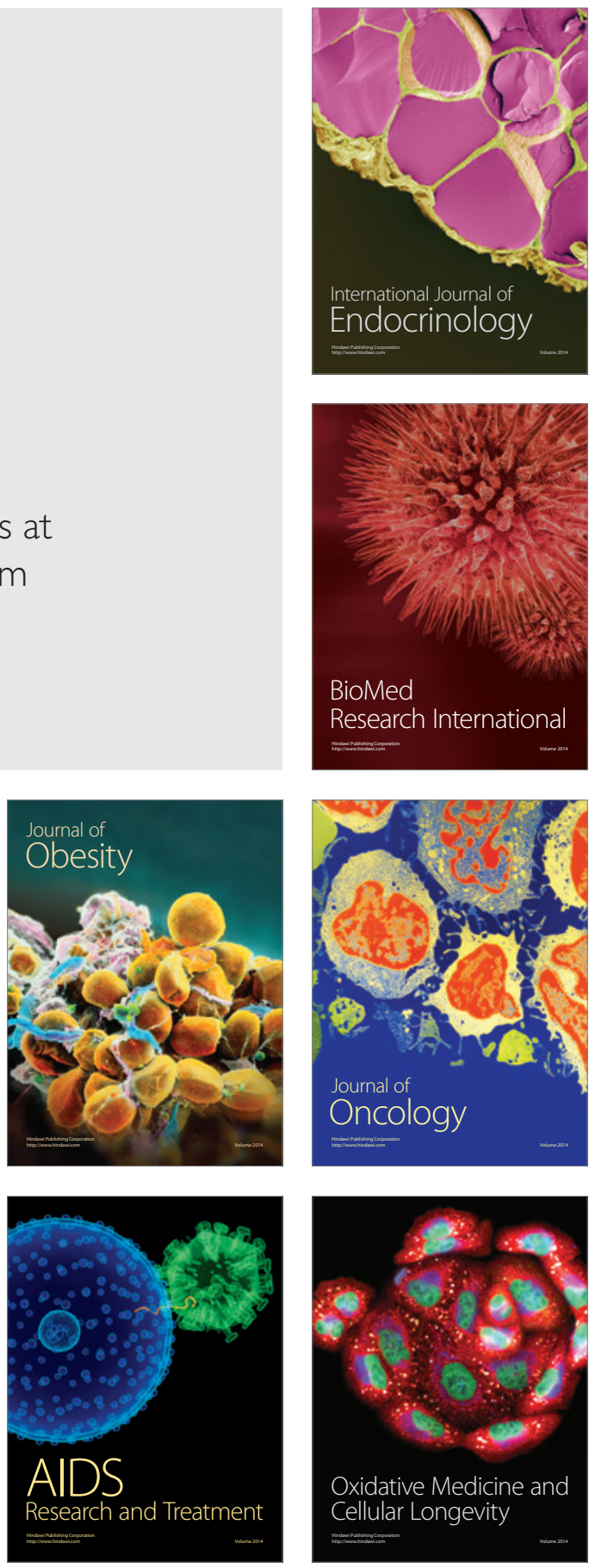